\title{
On Characterization Through Syntactic Foregrounding in Everyday Use
}

\author{
ZHENG Li-sha, ZHANG Shun-sheng \\ University of Shanghai for Science and Technology, Shanghai, China
}

\begin{abstract}
Language foregrounding is the artistically motivated deviation of language, with which readers' attraction is drawn to the author's attention so that the effect of literary depiction is enhanced. The present paper analyzes the sentence length, ellipsis, and inversion in Everyday Use from the perspective of syntax to discuss their effects on characterization.
\end{abstract}

Keywords: Everyday Use, stylistics, syntactic foregrounding, characterization

\section{Introduction}

As an important term in stylistics, foregrounding refers to the artistically motivated deviation of the norms of the ordinary language from the "background" to draw readers' attention to the author's. Foregrounding is mainly reached through two language phenomena, deviation and prominence (Cui, 2006). Reflecting on different language levels, it has different features and techniques. For syntactic foregrounding, it can be reached through the application of inversion, ellipsis of sentence elements, and the intentional use of too long or too short a sentence (Zhao \& Gong, 2007).

In Alice Walker's short story, Everyday Use, the language feature of the heroine is of great diversity on syntactic level. Written in the times when the Blacks were repressed hard by the Whites, Everyday Use depicts the attitudes of a black family — the mother and her two daughters Dee and Maggie — to the ownership and values of their traditional cultural heritages. The story is narrated from the internal point of view and presented through "I", the mother's eyes. Through her language, the inner world of the characters-their attitudes and judgments-is revealed. From the syntactic perspective, this paper is intended to analyze the functional significance of foregrounding in Everyday Use as a vehicle for characterization.

\section{Sentence Length: Description and Discussion}

Generally, the sentences in Everyday Use are not very long while comparatively longer and more complete sentences mainly occupy the story; and apart from the conversations, only around 25 sentences are written in short sentence. In this story, longer sentences are mainly used to depict the scenes and activities involved while

ZHENG Li-sha, Master of Arts (Student), College of Foreign Languages, University of Shanghai for Science and Technology, Shanghai, China.

ZHANG Shun-sheng, Master's Degree, professor, College of Foreign Languages, University of Shanghai for Science and Technology, Shanghai, China. 
shorter sentences are directly applied to intimate or even reveal the standpoints of the heroines and to foreshadow the plot. Lied among the relatively longer sentences, the short sentences are prominent, which gives meanings to the understanding of the roles and the theme of the story.

\title{
Mother's Love for Current Life and Traditional Inheritances
}

\author{
Example-1: \\ It is not just a yard. (George \& Barbara, 1999, p. 1967) \\ Example-2: \\ It is like an extended living room. (George \& Barbara, 1999, p. 1967)
}

The above sentences are abstracted from the mother's description on her yard. According to them, it is prominent that the comfort and happiness brought about by the clean yard are of great importance for her. After affirming the value of the yard, Alice Walker details the yard's cleanness with a long sentence. The depiction shows that for "I" (the mother), it is a pride and pleasure to have such a yard, where by the elm tree leisure time can be spent with families and friends in the breezes. Besides, in the mother's mind, the yard is not an occasional object built but a traditional structure in their family's habitat. Before the previous burnt house, there is still a similar yard with "a sweet gum tree", which has provided them with happy times as well. It happens that the house used to be lived by Big Dee and Stash also has a yard in case and it is just the tree growing there that has provided wood for making the dasher in use now (George \& Barbara, 1999). Therefore, for the mother, the importance of the yard is not only the comfort it provides at this moment but also the memory of the traditional living habit of her family.

Example-3:

She had hated the house that much. (George \& Barbara, 1999, p. 1968)

Example-4:

I have deliberately turned my back on the house. (George \& Barbara, 1999, p. 1968)

The mother's joy obtained from the yard positively reveals her love and inheritance of the culture while on the other hand, when Dee comes back, her "discard" of the house by turning back on has the same effect. Dee is perfect in the mother's mind so the mother is in awe of her (Zhao, 2008). As she knows that Dee hates the house (Example-3), she chooses to cater to Dee by ignoring the house as well (Example-4). However, though she does this "deliberately", she still cannot help recollecting every detail of the house in mind. Alice Walker has used three long sentences to describe the mother's memory on the house and from the roof to the window, every single detail of the house is indelible to her. Regarding it as the inheritance of that burnt house, she duplicates it from the burnt one and makes herself feel alive in the old one inherited from the family again. However, just for her daughter's favor, she has to hide her sincere feelings to show indifference, which provides a hint for her later decision of giving Maggie the quilts as she is always the tradition lover and culture inheritor. 


\title{
Mother's Attitude to the Use of the Quilts, the Heritage
}

\author{
Example-5: \\ I reckon she would. (George \& Barbara, 1999, p. 1972) \\ Example-6: \\ I hope she will! (George \& Barbara, 1999, p. 1972)
}

These two short sentences appear when the mother thinks about the use of the quilts. In the writings of the Black American writer, Alice Walker, the symbolic meaning of “quilt” is not only the symbol of woman's solidarity but the symbol of cultural heritage. The quilt in Everyday Use records the history of the family as well as the development of the country and the efforts that Black Americans made on it (Zhang \& Zhao, 2003). It is the first time that the mother expresses her attitudes to the traditional cultural heritages bluntly without fear and concerns on others' ideas. The arguments on the use of the quilts that whether it should be hung on the wall or taken as an everyday use are the climax of this story. When Dee blames that the quilt will be put to everyday use by Maggie (Example-5 and Example-6), the mother replies by exclaiming her position that she hopes the quilts will be used in Maggie's daily life as soon as possible as the quilts have been left unused for a long time (George \& Barbara, 1999). In fact, Dee is the first choice of the mother to use these quilts when she goes to attend college, but she refuses it as she thinks these two quilts are "old-fashioned" and "out of style” (George \& Barbara, 1999, p. 1972). In the argument, the mother successfully distinguishes two daughters' attitudes to the quilts' values; therefore, she makes her decision firmly (Zhao, 2008). During the arguments, the mother seems to be suffering from an epiphany as something hits her at the head of the top (George \& Barbara, 1999). According to her love and sense of inheritance for other goods that related to her culture, her final giving the quilts to Maggie is not on impulse but an externalization of the deep love and understanding for culture heritage.

\section{Ellipsis for Characterization and Inversion for Prominence}

Ellipsis is omission and rearrangement of the constituents of a sentence. It has the effect of adding to the rhythm of narration, emotional impact and serving the cause of characterization (Hou, 2008). In this story, ellipsis is mainly employed to characterize Dee's disposition.

Example-7:

And Dee. (George \& Barbara, 1999, p. 1968) (Complete Sentence: And Dee was there.)

This ellipsis appears when the mother is recalling the fire. After using a long sentence to state the situation where Maggie and the mother are trapped in the fire, Walker writes this ellipsis which adds to the switch of readers' focus on Dee. At such a life-and-death moment, Dee is just standing there without crying and calling for help to save her only family but concentrates on the destruction of the house which she dislikes. She is so cruel and shows no concern for her family members. The ellipsis leaves "Dee", the name only on the central of stage, adding to the possible anger and disappointment of the mother as she ironically asks "Why don't you do a dance around the ashes?”(George \& Barbara, 1999, p. 1968). Besides, as Dee is so indifferent to her closest family, it is not at all surprising that she cannot have a deep memory of other families, not to mention the culture and tradition 
passed from them and carried by the heritages. In that situation, the mother's anger is shown in an ironic question without clearly pointing out what the anger is for. But through the analysis of the mother's deeply buried love for the culture and further plot, it can be indicated that the anger is not only about her ignoring of her and Maggie, but possibly also for her indifference to the family heritage, the house. Another two examples, "Dee, though" (George \& Barbara, 1999, p. 1968), when depicts her nature as no hesitation and “Dee next” (George \& Barbara, 1999, p. 1969) when depicts her appearance, have the similar effect to put the focus on Dee. Her deliberate imitation of the language and costume in Black Cultural Movement confirms her preservation and understanding of the heritage and culture is not in the proper way (Hu \& Cai, 2007).

Another syntactic technique, inversion, has also been employed to add to characterization of Dee as well. It reverses the normal sentence order and in so doing arrests attention and lays emphasis on the inverted word or phrase (Hou, 2008).

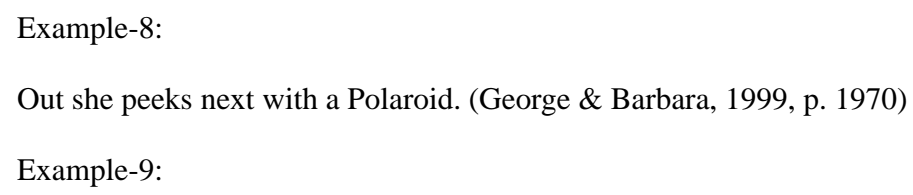

Examples 8 and 9 both put the main clause before the adverbial; therefore, the main information is delayed, similar to a periodic sentence, by which a sense of mystery and curiosity is engineered (Hou, 2008). When the reader finally gets the main information with suspense, the information in the end of the sentence is given prominence to. In Example-8, the word "Polaroid" is at the end of the sentence and as it represents the modern style, it again confirms Dee's style of her own with the trend of the time (Liu \& Li, 2015). Dee comes back home for traditional items. After searching and getting the benches, the churn top and the dasher, Dee finally exposes her intention to ask for the quilts (Example-9). The quilt is a key symbol of black tradition and culture (Liu \& Li, 2015) while Dee just wants to collect it to hang up. The sudden revelation through the inversion structure adds to the characterization of Dee as a collector of traditional heritages rather than a sincere lover and it also promotes the development of the story to the climax.

\section{Conclusion}

In Everyday Use, Alice Walker applies different levels of stylistic techniques to enhance the characterization and theme expression. Focused on the syntactic foregrounding, this paper discusses the effect of using short sentences, ellipsis, and inversion on characterization. Through the coordinate use of long and short sentence, the mother's love and inheritance of culture heritage was revealed and reversely. Dee's indifference to the family relationship and blind preservation was exposed through ellipsis and inversion. Simply through the analysis of foregrounding technique at the syntax level can the inner world of the heroines be found. It is Alice Walker's operational command of the language that enhance the comprehensive reveal of the judgement and understanding of the black to their traditional cultural heritage. 


\section{References}

Cui, H. G. (2006). The concept of foregrounding and literary stylistic analysis. Journal of Peking University (Philosophy \& Social Sciences), (S1), 123-128.

George, P., \& Barbara, P. (Eds.). (1999). Everyday use. In The American tradition in literature (pp. 1967-1972). USA: The McGrew-Hill Co.

Hou, W. (2008). Literary stylistics. Shanghai: Shanghai Foreign Language Education Press.

Hu, Z. Q., \& Cai, S. Q. (2007). Symbolic meanings of the feminism characters in Everyday Use. Hubei Social Sciences, (4), 144-146.

Liu, Q., \& Li, T. (2015). A stylistic analysis of language foregrounding in Alice Walker's Everyday Use. Journal of Shenyang Agricultural University (Social Sciences Edition), 17(5), 630-634.

Zhang, F., \& Zhao, J. (2003). Quilting and ethno-cultural memory: A cultural interpretation of Alice Walker's Everyday Use. Shandong Foreign Language Teaching, (5), 16-18.

Zhao, S. M., \& Gong, J. G. (2007). The theory of foregrounding and its application to the translation of novels. Foreign Language Research, (2), 128-132.

Zhao, X. N. (2008). Alice Walker's “Women and Feminism” complex: Analysis of the mother in Everyday Use. Movie Literature, (23), 158-159. 